\title{
Porous Electrospun Nanofiber from Biomass-Based Polyester Blends of Polylactic Acid and Polybutylene Succinate
}

\author{
Manisara Phiriyawirut*, Kanokwan Sarapat, Sutasinee Sirima, Anrasee Prasertchol \\ Department of Tool and Materials Engineering, Faculty of Engineering, King Mongkut's University of Technology Thonburi, \\ Bangkok, Thailand \\ Email: *manisara.pee@kmutt.ac.th
}

How to cite this paper: Phiriyawirut, M., Sarapat, K., Sirima, S. and Prasertchol, A. (2019) Porous Electrospun Nanofiber from Biomass-Based Polyester Blends of Polylactic Acid and Polybutylene Succinate. Open Journal of Polymer Chemistry, 9, 1-15. https://doi.org/10.4236/ojpchem.2019.91001

Received: October 9, 2018

Accepted: January 30, 2019

Published: February 2, 2019

Copyright () 2019 by author(s) and Scientific Research Publishing Inc. This work is licensed under the Creative Commons Attribution International License (CC BY 4.0).

http://creativecommons.org/licenses/by/4.0/

\begin{abstract}
We studied the electrospinning process of the blend of polylactic acid (PLA) and polybutylene succinate (PBS). The blend PLA/PBS ratio 95/5, 90/10, $85 / 15$ and $80 / 20 \mathrm{wt} \%$ were prepared by dissolved in mixture of solvent between dichloromethane (DCM) and $N, N$-dimethylformamide (DMF) at ratio $3 / 1$. The suitable condition for electrospun of the blend was $17 \%$ wt concentration, $16 \mathrm{kV}$ and $18 \mathrm{~cm}$ projection distance. The round fiber with pore on the surface was observed. Increasing content of PBS in the blend impact to the diameter of fibril decreased from 1350, 1290, 1210 and $1170 \mathrm{~nm}$, respectively; while the pore on the surface changes from circle to oval shape. Regarding the thermal properties, blending of PBS increases the glass transition temperature $\left(\mathrm{T}_{\mathrm{g}}\right)$ of PLA without affect to the melting temperature $\left(\mathrm{T}_{\mathrm{m}}\right)$ of the electrospun nanofibers. The best tensile properties of PLA/PBS nanofibers were achieved at blend ratio of 95/5, and Young's modulus is increased comparing to those of the pure electrospun fibers.
\end{abstract}

\section{Keywords}

Electrospinning, Polymer Blend, PLA, PBS, Nanofiber

\section{Introduction}

Recently, it has been increasing interested in method to produce polymer fiber using electrostatic spinning technique or electrospinning, which produces fibers diameter in the range of sub-micro meter down to nanometer. The electrospinning technique is a simple and versatile method which utilizes a high voltage source to inject charge of a certain polarity into a polymer solution or melt and 
then accelerated toward a collector of opposite polarity. It's capable to produce fiber in biological size scale, and created a new interested in electrospinning for drug delivery application. The fibers exhibit several interesting characteristics, for example, a high surface area to mass or volume ratio, high density of pores in sub-micrometer length scale, vast possibilities for surface functionalization [1] [2]. These unique properties have triggered a broad range of potential applications, including nanocomposites [3], scaffolds for tissue engineering [4], sensors [5], protective clothing and filtration membranes [6], magneto-responsive fibers [7], super hydrophobic membranes [8], and especially drug delivery [9].

Both synthetic and natural polymer nanofibers were produced from electrospinning such as aliphatic polyester, polyvinyl alcohol and polyamide. Among the various aliphatic degradable polyesters, polylactic acid (PLA) has been considered as one of the most interesting and promising biodegradable materials and has been the material of choice to be used in various medical applications, such as surgical sutures [10] drug-delivery vehicles [11] and bone fixtures [12]. However, the drawbacks of PLA are hard and brittle.

In order to improve the properties and explore the applications of the material, several approaches have been developed to modify it. Blending with aliphatic polyester was found to be an effective method due to containing the same functionality. The blending with flexible polymers would enhance PLA flexibility [13] [14] [15] [16] [17]. Polybutylene succinate (PBS) was selected as a material to blend due to similarity in physical and thermal properties to polyethylene (PE), which shows good flexibility [18] and easy to process at relatively low coat as compared to PLA [19]. Moreover, a number of studies on PLA/PBS blends have been reported [20]-[25]. Although Park and Im [20] found that PLA is miscible with PBS in amorphous region, however, recent studied have concluded that PLA is immiscible with PBS [21]. Some research reported that adding PBS enhances the cold-crystallization of PLA [22]. The cold-crystallization for quenched PLA/PBS blend occurs at lower temperature than that for a quenched PLA [23]. It is interesting that blending of PLA and PBS to make fiber gives better quality at smaller diameter to less brittle. The previous study to make the fiber of this blending material using melt pinning method was reported [24].

In this work, electrospinning was applied to fabricate ultrafine fibers from pure PLA, PBS and their blends. Chemical structure of PLA and PBS were showed in Figure 1. Morphology and sizes of the as-spun fibers were investigated using scanning electron microscopy (SEM) and thermal behaviour and crystalline structure of the as-spun fibers were investigated using differential scanning calorimetry (DSC) and X-ray diffraction (XRD). In addition, tensile

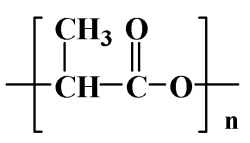

Polylactic acid, PLA

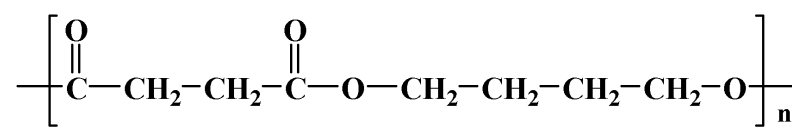

Polybutylene succinate, PBS

Figure 1. Chemical structure of PLA and PBS. 
properties of the as-spun PLA/PBS blend nanofiber mats were also investigated.

\section{Experimental}

\subsection{Materials}

Polylactic acid, PLA $\left(\mathrm{MW}=5.0594 \times 10^{4}\right)$ was supplied by Nature Work. Polybutylene succinate, PBS $\left(\mathrm{MW}=5.8207 \times 10^{4}\right)$ was supplied by Mitsubishi Chemical Corporation (AZ91TN). Dichloromethane, DCM (analytical grade) was supplied by RCI Labscan Limited, Thailand. $N, N$-dimethyl formamide, DMF (analytical grade) was supplied by Lab scan Asia Co., Ltd., Thailand. All of the above chemicals were used as received.

\subsection{Preparation of Blend Nanofibers}

To prepare as-spun PLA/PBS blend nanofiber mats, solutions of PBS and PLA were prepared separately with concentration of $17 \%(\mathrm{w} / \mathrm{v})$ by using DCM and DMF with ratio $3 / 1$ as the solvent. The solutions of PLA/PBS blends were weight ratios of $100 / 0,95 / 5,90 / 10,85 / 5,80 / 20$ and $0 / 100$, respectively. The polymer blend solution was fabricated into nanofibers using an electrospinning apparatus at $25^{\circ} \mathrm{C}$ with applied electrostatic field strength at $16 \mathrm{kV} / 18 \mathrm{~cm}$ of projection distance.

\subsection{Rotational Viscosity}

Solution rotational viscosity of the as-prepared PLA/PBS blend solutions were measured using a rotational viscometer (VISCO STAR Plus L) with carried out at room condition.

\subsection{Scanning Electron Microscopy}

Morphology of the blend as-spun nanofiber mats was evaluated by scanning electron microscopy (SEM). The samples were coated with gold under vacuum and then observed by SEM (JEOL JSM 6610LV).

\subsection{X-Ray Diffraction}

Crystal structures of PLA, PBS and the blend as-spun nanofiber mats were investigated with an X-ray diffraction (XRD) technique with a diffractometer (D8-Discover model from Bruker AXS). The XRD data were collected at 2 theta from 5 to 35 in a step of $0.02^{\circ}$.

\subsection{Differential Scanning Calorimetry}

Glass transition temperature $\left(\mathrm{T}_{\mathrm{g}}\right)$, melting temperature $\left(\mathrm{T}_{\mathrm{m}}\right)$ values, crystallization temperature $\left(\mathrm{T}_{c}\right)$ and enthalpy of melting of blend as-spun nanofiber mats were investigated using DSC (Perkin Elmer DSC7). The samples were first heated and cooled over a temperature range of $-60^{\circ} \mathrm{C}$ to $230^{\circ} \mathrm{C}$ at a rate of $10^{\circ} \mathrm{C} /$ min to set a standard thermal history, and heated again at a heating rate of $10^{\circ} \mathrm{C} /$ min over a temperature range of $-60^{\circ} \mathrm{C}$ to $230^{\circ} \mathrm{C}$ under nitrogen atmos- 
phere.

\subsection{Tensile Measurement}

The blend as-spun nanofiber mats were cut into a rectangle sheet $\left(2.5 \times 10 \mathrm{~cm}^{2}\right)$ according to ASTM D882-02 standard. The thickness of the as-spun mat was about $0.25 \mathrm{~mm}$. Tensile testing was performed on the PLA/PBS blend as-spun mat along with electro-spinning direction using a Texture analyzer (Stable Micro System TA. XT plus) at a crosshead speed of $20 \mathrm{~mm} / \mathrm{min}$. The average data value and the standard deviation value from five samples were calculated and recorded.

\section{Results and Discussion}

\subsection{Rotational Viscosity of the PLA/PBS Blend Solution}

The rotational viscosity of the as-prepared PLA/PBS blend solutions at different weight ratios in DCM/DMF:3/1 solution is listed in Table 1 . The viscosity of the blend solutions was decreased by addition of PBS comparing to pure PLA solution. The viscosity decreased monotonically with further increase in the PBS content. It is possible that the PBS molecule interrupt the intra-molecular force of the PLA, leading to higher mobility of PLA molecule in the blend solution, and consequence to interpenetrating of the PBS molecule in to space between chains of PLA. Thus, the higher content of the PBS in the blend solution causes of lowering the viscosity, which is also lower than the PBS, itself.

\subsection{Fiber Morphology of the Electrospun PLA/PBS Blend Nanofibers}

Scanning electron micrographs of the as-spun PLA/PBS fibres that prepared using a various blend ratio were shown in Figure 2 and Figure 3.

Obviously, the as-spun PLA fibers (100/0) appeared as circular in their cross-section and pore-like structure appeared at the surface of fibers, which is in good agreement to the previous report [26]. The pore-like structure on the

Table 1. Apparent rotational viscosity of pure and blend solutions of PBS (17\% (w/v)) and PLA (17\% (w/v)) in DCM/DMF solution at room temperature and average fiber diameter and fiber content of as-spun PLA/PBS blend nanofibers.

\begin{tabular}{cccc}
\hline PLA/PBS blend ratio & $\begin{array}{c}\text { Rotational viscosity } \\
(\mathrm{cP})\end{array}$ & $\begin{array}{c}\text { Fiber diameter } \\
(\mathrm{nm})\end{array}$ & $\begin{array}{c}\text { Fiber content } \\
\left(\text { count/ } 100 \mu \mathrm{m}^{2}\right)\end{array}$ \\
\hline $100 / 0$ & $56.4 \pm 2.4$ & $1360 \pm 570$ & 25 \\
$95 / 5$ & $54.4 \pm 2.0$ & $1350 \pm 680$ & 19 \\
$90 / 10$ & $53.7 \pm 2.0$ & $1290 \pm 520$ & 21 \\
$85 / 15$ & $50.2 \pm 1.3$ & $1210 \pm 360$ & 20 \\
$80 / 20$ & $43.5 \pm 0.8$ & $1170 \pm 330$ & 21 \\
$0 / 100$ & $54.6 \pm 0.7$ & $550 \pm 200$ & 68 \\
\hline
\end{tabular}

The applied electrostatic field strength was $16 \mathrm{kV} / 18 \mathrm{~cm}$. 

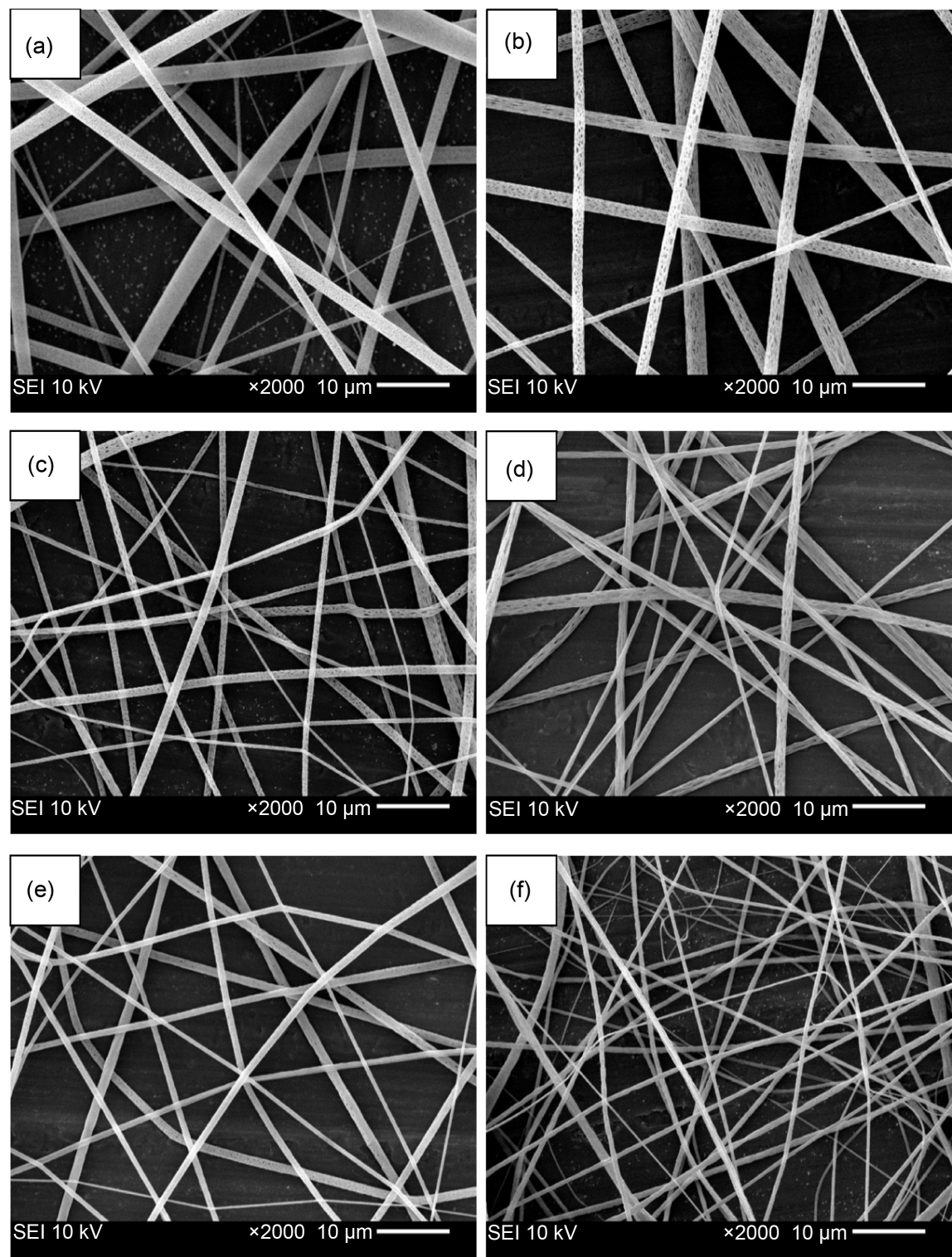

Figure 2. SEM images (magnification $2000 \times$, scale bar $=10 \mu \mathrm{m}$ ) of as-spun products from blend solutions of PLA/PBS in various blend compositions (w/w): (a) 100/0, (b) $95 / 5$, (c) $90 / 10$, (d) $85 / 15$, (e) $80 / 20$ and (f) 0/100, respectively. The applied electrostatic field strength was $16 \mathrm{kV} / 18 \mathrm{~cm}$.

surface of the fibers is postulated to be a result of the high volatility of the solvents and the microscopic phase separation of the solutions at the surface of the ejected, charged jet that occurred very rapidly during electrospinning. With the latter notion in mind, the solvent-rich phase readily transformed into the pore-like structure. On the other hand, the as-spun PBS fibers (0/100) appeared to be circular in their cross-section and the smooth surface. Interestingly, even the same concentration and same range of solution viscosity, as-spun PBS fibers were found to lower average diameter as compared to as-spun PLA fiber.

When PLA blends with PBS were electrospun, it was found that the presence of PBS does not affect substantially the morphology of the PLA matrix phase. 

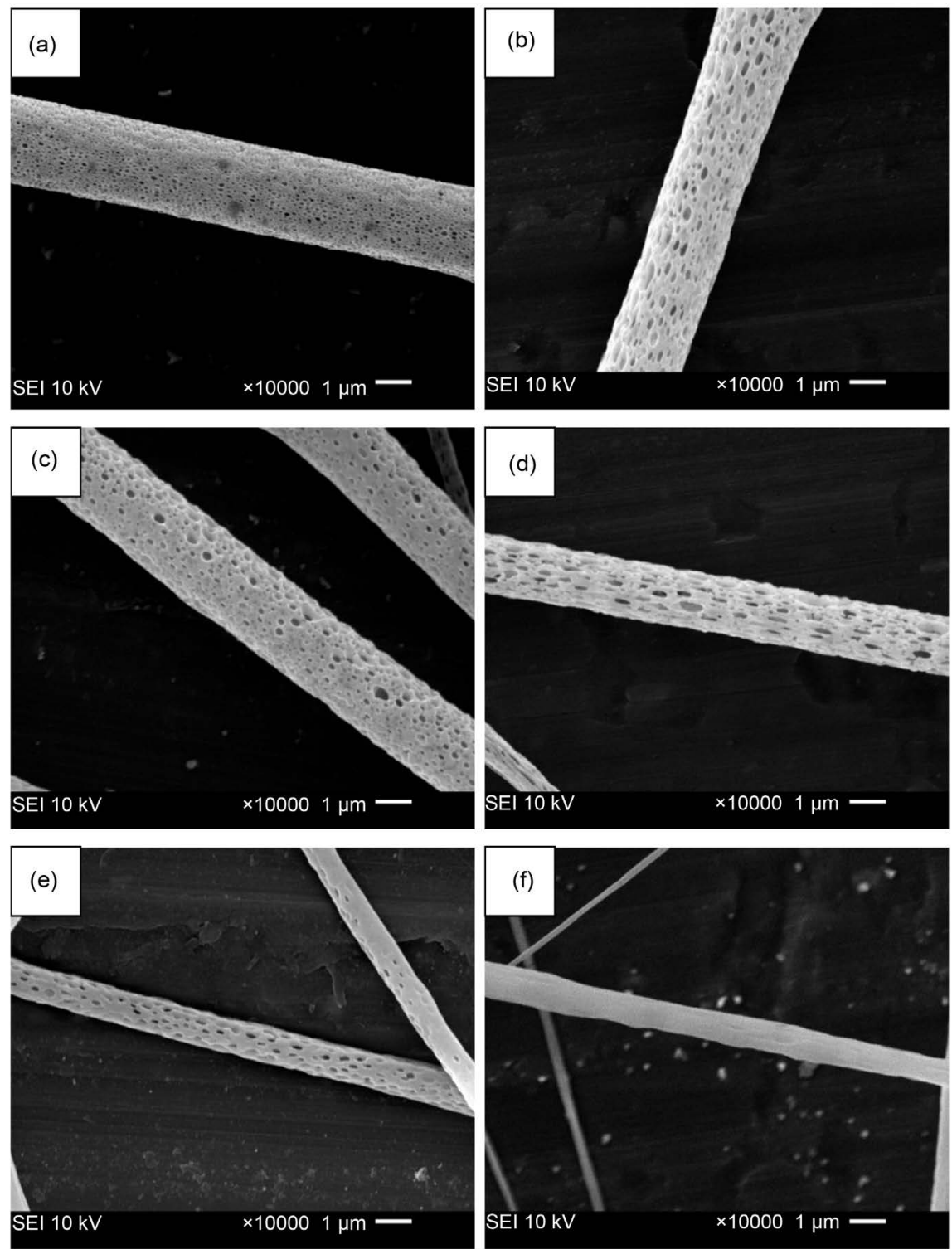

Figure 3. SEM images (magnification $10,000 \times$, scale bar $=1 \mu \mathrm{m}$ ) of as-spun products from blend solutions of PLA/PBS in various blend compositions (w/w): (a) 100/0, (b) $95 / 5$, (c) $90 / 10$, (d) $85 / 15$, (e) $80 / 20$ and (f) $0 / 100$, respectively. The applied electrostatic field strength was $16 \mathrm{kV} / 18 \mathrm{~cm}$.

The as-spun blend fibers were still circular in cross-section with pore-like structure. It is interesting that as increasing PBS content, diameter of pore-like structure increased. This might be the effect of lowering viscosity of polymer blend solution as increasing PBS content, and lead to easy expansion of solvent-rich phase during electrospinning.

However, their diameters were found to decrease with increasing amount of added PBS solution (see Table 1), most likely a result of decreasing in the viscosity of the blend solutions: hence, a decrease in the viscoelastic force in comparison to unchanged of the Coulombic repulsion force. Similar effects were noted by previous work [26] in studies on the effect of blend ratio on the diame- 
ter of electrospun PLA/hexanoyl chitosan. In the study, the size of as-spun fibers were decreased when the blend solutions containing hexanoyl chitosan solution less than or equal to $50 \%(\mathrm{w} / \mathrm{w})$, and the size decreased proportionally to the amount of the hexanoyl chitosan solution in the blend.

\subsection{Crystal Morphology of the Electrospun PLA/PBS Blend Nanofibers}

Figure 4 illustrates the XRD patterns of the as-spun PLA/PBS fibres, which was prepared using a various blend ratio. For pure as-spun PLA fibers, the obtained XRD pattern showed only one broad diffraction peak centering at the $2 \theta$ of about $16.5^{\circ}$ and $17.9^{\circ}$, which is in good agreement with the earlier reported for the injected PLA sample [27]. The as-spun PLA fibers (100/0) had a pseudo-orthorhombic unit cell structure which were assigned to the (110) and (203) planes, respectively. While, the as-spun PBS fibers (0/100) had a monoclinic unit cell structure with the characteristic XRD peaks at $19.5^{\circ}$ and $22.5^{\circ}$, which were assigned to the (020) and (110) planes, respectively, and it is in a good agreement to previous report [28].

For the as-spun PLA/PBS fibers, the obtained diffraction patterns apparently exhibited only one broad diffraction peak centering at about the same $2 \theta$ value of the pure as-spun PLA fibers. The intensity of the XRD peak at $2 \theta$ of about $16.5^{\circ}$ and $17.9^{\circ}$ were decreased at the present of PBS in the blend. This suggests that the percentage crystallinity of the PLA phase decreased with increasing PBS content.

It is obvious that present small amount of PBS in the blend could enhance the crystallinity of the PLA, and it is in a good agreement with the hypothesis of the PBS could interpenetrate into the PLA during solution blending, and consequence in modification the crystallinity of the PLA, which could be observed in

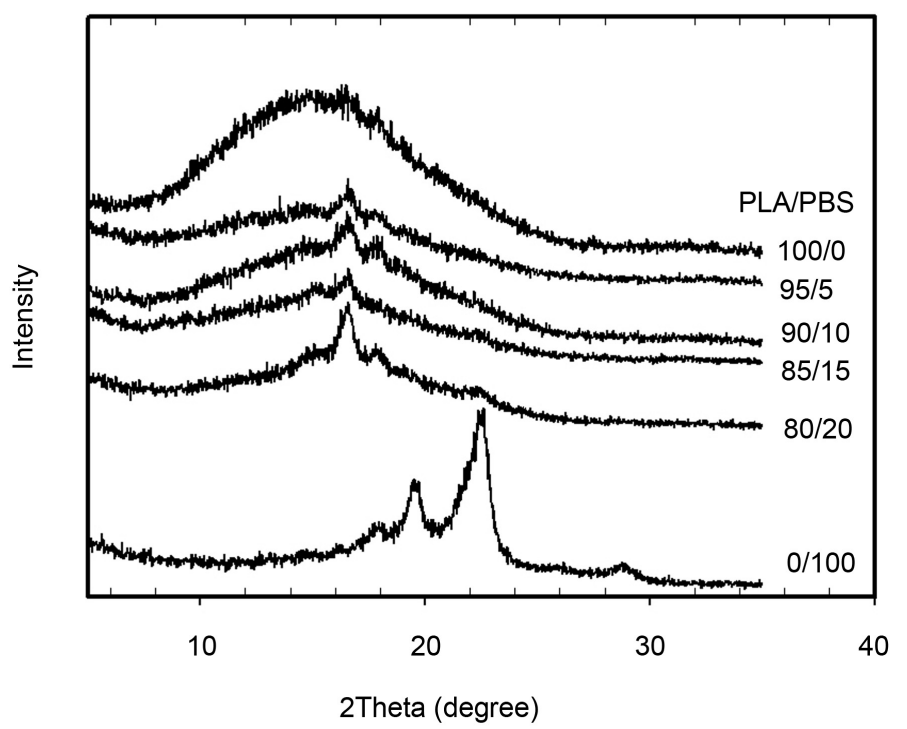

Figure 4. XRD patterns of as-spun products from blend solutions of PLA/PBS in various blend compositions. 
the XRD results.

\subsection{Thermal Properties of the Electrospun PLA/PBS Blend Nanofibers}

The DSC thermograms of the as-spun PLA, PBS and PLA/PBS fibers were shown in Figure 5 and summarized in Table 2. The crystallinity of PBS and PLA were calculated on the basic of the heat of fusion for PBS and PLA being 200 [29] and 93.7 J/g [25], respectively.

As-spun PBS fibers possess a glass transition temperature $\left(\mathrm{T}_{\mathrm{g}}\right)$ at $-31.2^{\circ} \mathrm{C}$, cold crystallization temperature $\left(\mathrm{T}_{\mathrm{cc}}\right)$ at ca. $75.5^{\circ} \mathrm{C}$, melting temperature $\left(\mathrm{T}_{\mathrm{m}}\right)$ at ca $104.9^{\circ} \mathrm{C}$, which has percentage of crystallization at $41.3 \%$. It has very high crystallinity comparing to those of ultrafine fibers of common polymers [30]. It

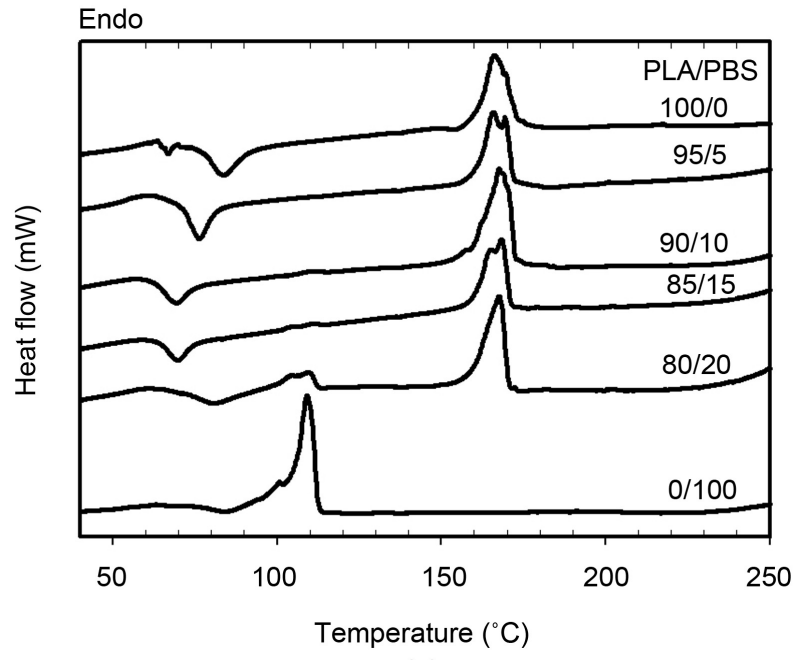

(a)

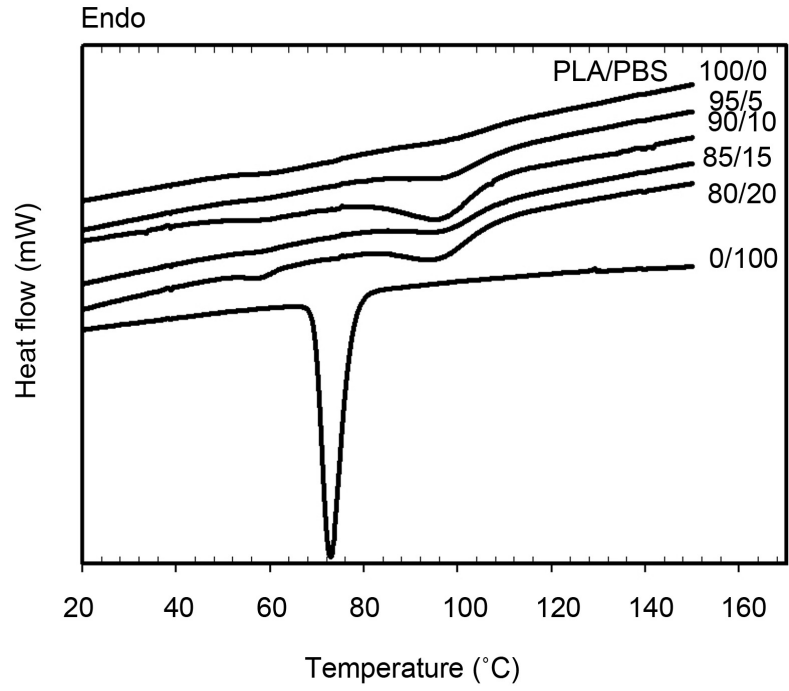

(b)

Figure 5. DSC thermograms of as-spun products from blend solutions of PLA/PBS in various blend compositions: (a) second heating scan and (b) cooling scan. The heating rate and cooling rate used were $10^{\circ} \mathrm{C} / \mathrm{min}$. 
Table 2. Thermal properties form DSC data of as-spun products from blend solutions of PLA/PBS in various blend compositions.

\begin{tabular}{ccccccccccc}
\hline $\begin{array}{c}\text { PLA/PBS } \\
\text { blend } \\
\text { ratio }\end{array}$ & $\begin{array}{c}\mathrm{T}_{\mathrm{g}} \\
\left({ }^{\circ} \mathrm{C}\right)\end{array}$ & $\begin{array}{c}\mathrm{T}_{\mathrm{m}} \\
\left({ }^{\circ} \mathrm{C}\right)\end{array}$ & $\begin{array}{c}\mathrm{T}_{\mathrm{cc}} \\
\left({ }^{\circ} \mathrm{C}\right)\end{array}$ & $\begin{array}{c}\Delta \mathrm{H}_{\mathrm{m}} \\
(\mathrm{J} / \mathrm{g})\end{array}$ & $\begin{array}{c}\mathrm{X}_{\mathrm{c}} \\
(\%)\end{array}$ & $\begin{array}{c}\mathrm{T}_{\mathrm{g}} \\
\left({ }^{\circ} \mathrm{C}\right)\end{array}$ & $\begin{array}{c}\mathrm{T}_{\mathrm{m}} \\
\left({ }^{\circ} \mathrm{C}\right)\end{array}$ & $\begin{array}{c}\mathrm{T}_{\mathrm{cc}} \\
\left({ }^{\circ} \mathrm{C}\right)\end{array}$ & $\begin{array}{c}\Delta \mathrm{H}_{\mathrm{m}} \\
(\mathrm{J} / \mathrm{g})\end{array}$ & $\begin{array}{c}\mathrm{X}_{\mathrm{c}} \\
(\%)\end{array}$ \\
\hline $100 / 0$ & 76.4 & 160.7 & 114.9 & 17.0 & 18.1 & - & - & - & - & - \\
$95 / 5$ & 70.3 & 160.4 & 108.9 & 22.3 & 23.8 & - & - & - & - & - \\
$90 / 10$ & 62.4 & 160.3 & 108.2 & 21.4 & 22.8 & - & - & - & - & - \\
$85 / 15$ & 61.7 & 160.2 & 108.1 & 20.3 & 21.7 & - & 101.2 & 72.4 & 11.3 & 5.7 \\
$80 / 20$ & 73.4 & 160.6 & 106.7 & 19.0 & 20.3 & -30.1 & 104.9 & 73.8 & 12.1 & 6.1 \\
$0 / 100$ & - & - & - & - & - & -31.2 & 104.9 & 75.5 & 82.5 & 41.3 \\
\hline
\end{tabular}

was reported that the crystallization of electrospun polymer was retarded because the rapid solidification of fiber prohibits crystallinity of polymer. Although the crystallization of the as-spun PBS fibers was retarded, the PBS fibers showed high crystallinity due to its high crystallization rate [31]. The high crystallinity of as-pun PBS fibers was confirmed by XRD which showed strong intensity of diffraction peak.

While as-spun PLA fibers possess a glass transition temperature $\left(\mathrm{T}_{\mathrm{g}}\right)$ at $76.4^{\circ} \mathrm{C}$, cold crystallization temperature $\left(\mathrm{T}_{\mathrm{c}}\right)$ at ca. $115^{\circ} \mathrm{C}$, melting temperature $\left(\mathrm{T}_{\mathrm{m}}\right)$ at ca. $161^{\circ} \mathrm{C}$, which has percentage of crystallization at $17 \%$. This result was in accordance to others study in thermal behavior of PLA-based electrospun fibers [32]. Again, the crystallinity of as-spun PLA fiber was lower than those of the corresponding as-cast films [33]. A similar effect was observed by Dhanalakshmi et al. [34] in a study of thermal properties of electrospun Nylon 11 nanofibers. In that case, electrospun fibers showed higher crystallinity than the melt-crystallized samples.

For the as-spun PLA/PBS fibres, DSC thermograms show only thermal characteristic of PLA phase when the PBS content in the range of 5\%-10\%. When increasing PBS content to $15 \%-20 \%$, DSC thermograms show both thermal characteristic of PLA and PBS phase.

The $\mathrm{T}_{\mathrm{g}}$ of as-spun blend fibers were shifted to low temperature when increased PBS content. Except 20\% concentration of PBS, the $\mathrm{T}_{\mathrm{g}}$ was increased again up to almost the same $\mathrm{T}_{\mathrm{g}}$ value of PLA. However, $\mathrm{T}_{\mathrm{g}}$ of as-spun blend fibers was still higher than as-spun PBS fibers. At "low" PBS contents (i.e. 15 $\mathrm{wt} \%$ ), decreasing $\mathrm{T}_{\mathrm{g}}$ of the blend products from pure PLA could be a result from miscibility between PLA and PBS molecules in the amorphous phase. Further increasing PBS content, phase separation between PLA and PBS molecules takes place as observing of two $T_{g}$ values in thermogram. This result was in a good agreement to the previous report [16] but $\mathrm{T}_{\mathrm{m}}$ was not much changed.

Crystallinity of PLA and PBS electrospun fiber were $18.1 \%$ and $41.3 \%$, respectively. It is interesting that percentage crystallinity of PLA phase in as-spun blend fibers was increasing ca. 5\% as comparing to pure PLA fibers, especially at 
PLA/PBS blending ratio 95/5. It's possible that PBS in the blend function as nuclei for PLA crystallization [35]. However, as increasing PBS content, phase separation became dominate and retard the crystallization of both PBS and PLA phase. It could be considered that the dilution effect may the reason of lowering crystallinity. The crystallinity of the blend linearly decreased as proportion to the increasing of PBS content.

\subsection{Mechanical Properties of the Electrospun PLA/PBS Blend Nanofibers}

Effect of PLA/PBS blending ratio to tensile strength, elongation at break and Young's modulus were shown in Figure 6.

Tensile strength of electrospun PBS mat was higher than electrospun of PLA mat, and the blend giving significantly increased in tensile strength comparing to neat electrospun of both materials. However, PBS content was not significantly affected to tensile strength. This result was difference from work of E. Hassan and coworker [25] which studied the properties of injected PLA/PBS blend. It was reported that PLA sample shows highest tensile strength follow by PLA/PBS sample, and decreased in tensile strength as increasing PBS content, which the PBS sample shows lowest in this properties. The different result may arise from different grade of materials and different in method of sample preparation. In case of electrospun fiber, smaller fiber (PBS and PLA/PBS electrospun fiber) has higher surface area per mass of materials than those of larger fiber (PLA electrospun fiber). This improvement on the blend and PBS mat give higher tensile strength than the PLA. The polymer blend mat, form homogeneous blending in polymer solution, which has better dispersion of PBS among the PLA giving better performance of the mat rather than pure PBS or PLA electrospun mat. It's interesting that the polymer blend mat shows significantly fiber join together which is obvious in the SEM image, which results of higher tensile strength than the mat from pure PLA and PBS.

Elongational at break (Figure 6(b)) increases gradually with PBS content increased, which is the effect of higher flexibility of PBS molecule than the PLA one. This result was in a good agreement to work of E. Hassan and coworker [25]. It was reported that injected PLA sample showed lowest elongation and PLA/PBS sample increased in elongation as increasing PBS content and PBS sample showed highest on this property. In case of electrospun fiber, elongational properties of PLA/PBS sample were increased at increasing of PBS content. The maximum values were observed at blending ratio of 80/20 which higher than those of neat PBS electrospun fiber. The neat electrospun PBS fiber $(\varnothing=$ $550 \pm 200 \mathrm{~nm}$ ) has smaller average diameter than those of electrospun PLA/PBS blend fiber ratio of $80 / 20(\varnothing=1170 \pm 330 \mathrm{~nm})$. It is known that smaller diameter fiber was break down prior larger diameter fibres during elongation. Moreover, from thermal properties from DSC technic indicated that electrospun PLA/PBS blend fiber ratio at $95 / 5,90 / 10$ and $85 / 15$ were miscible blend, while 


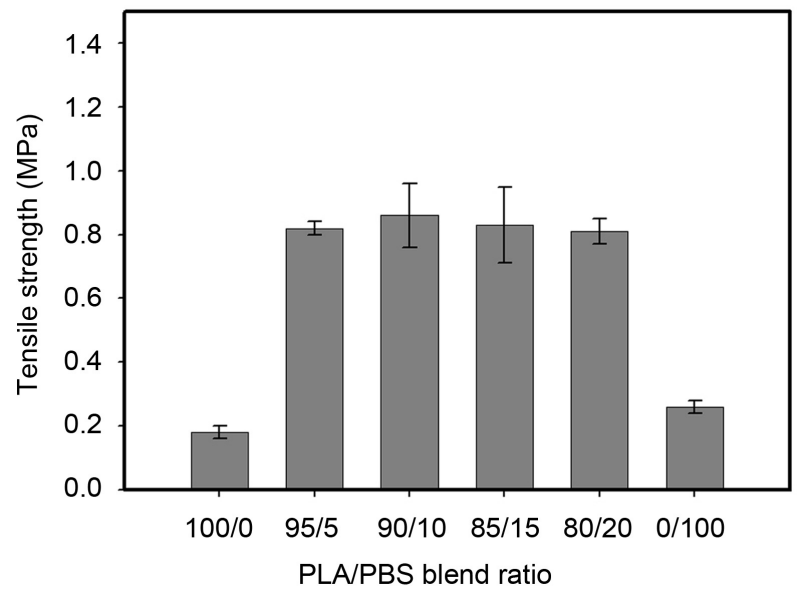

(a)

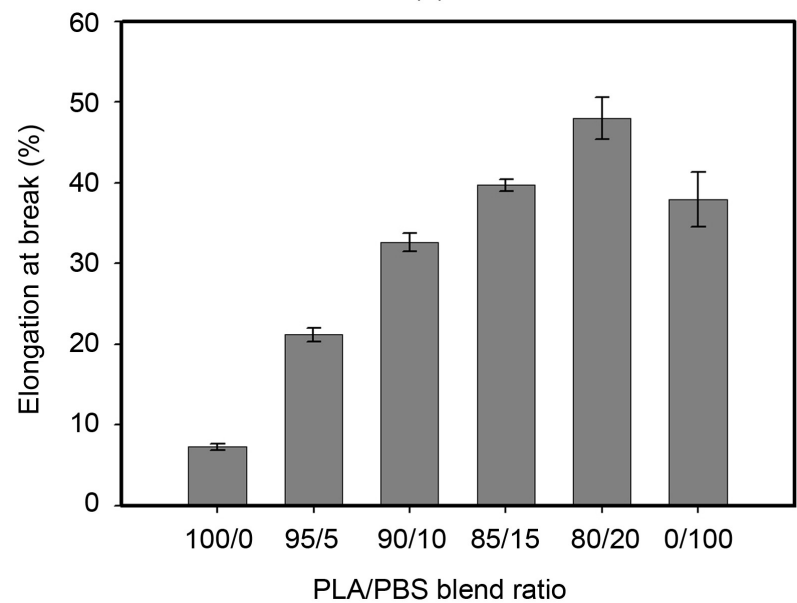

(b)

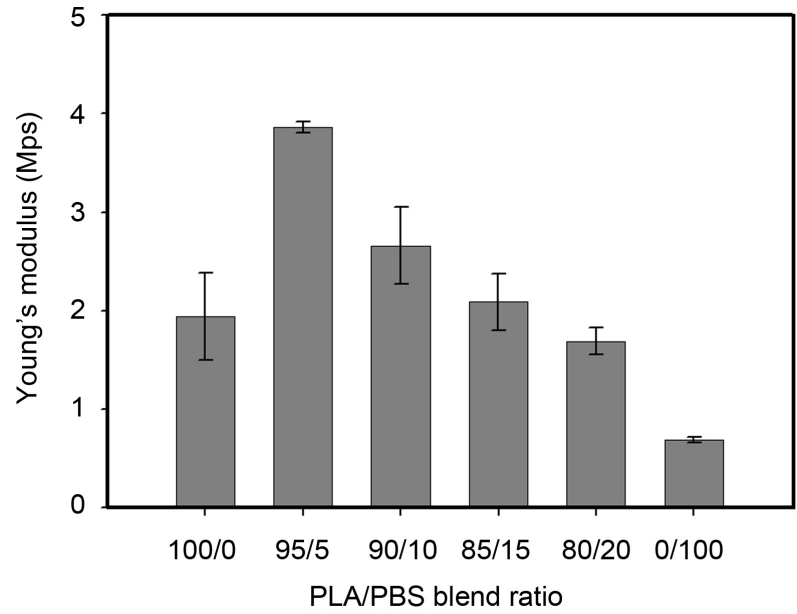

(c)

Figure 6. Tensile properties of as-spun products from blend solutions of PLA/PBS in various blend compositions: (a) tensile strength, (b) elongation at break and (c) Young's modulus.

blend ratio of 80/20 was immiscible blend. As increase PBS content, phase separation between PLA and PBS was dominated and finally completely immiscible blend. From work of Yokohara and Yamaguchi [23], it is suggested that entan- 
glement molecular weight of PLA was lower than those of PBS, thus PBS phase was more elongated than PLA phase. Even the blend ratio of 80/20 was immiscible, but larger PBS phase was enhanced elongation of the blend fiber.

Young's modulus (Figure 6(c)) is increased significantly when present small amount of PBS and decreased with the increasing of PBS content. The maximum values appeared with blend ratio at $95 / 5$. The results were caused by balancing between larger elongation at the same range of strength.

The electronspun of PLA/PBS blend nanofibers show good tensile properties, which is suitable to be used in some application. Electrospun PLA/PBS blend nanofiber at ratio of $95 / 5$, having maximum modulus, was perfected for high load application such as bulletproof vest. Meanwhile electrospun PLA/PBS blend nanofiber at ratio of $80 / 20$, giving maximum elongation and smallest diameter, is perfect to apply in filtration application or using as tissue scaffold in bio-engineering.

\section{Conclusion}

Porous electrospun nanofiber from biomass-based polyester blends of PLA and PBS was successfully prepared by an electrospinning process under various blend composition. The blend PLA/PBS ratios 95/5, 90/10, 85/15 and 80/20 wt\% were studied. Diameter of the electrospun fiber decreased with an increase of PBS content. The round fiber with pore on the surface was observed. It is PLA fiber characteristic when prepared by electrospinning process. Shape of the pore changes from circle to oval as increasing PBS content. Miscibility of electrospun PLA/PBS blend nanofibers was found from PBS content not more than $15 \mathrm{wt} \%$ which is detected by single $\mathrm{T}_{\mathrm{g}}$ of PLA phase. However, blending of PBS increases $\mathrm{T}_{\mathrm{g}}$ and crystallinity of PLA without affect to $\mathrm{T}_{\mathrm{m}}$ of as-spun blend fiber. Increasing of PBS content, elongation at break of the electrospun fiber mat was increased due to flexibility of PBS molecule but tensile strength was not significantly affected. PLA/PBS nanofibers at blend ratio of 95/5 showed highest Young's modulus (in range of investigation). In conclusion, electrospun PLA/PBS blend nanofibers were found to be a promising material to apply in many applications.

\section{Acknowledgements}

This work has been supported by Department of Tool and Materials Engineering, Faculty of Engineering, King Mongkut's University of Technology Thonburi.

\section{Conflicts of Interest}

The authors declare no conflicts of interest regarding the publication of this paper.

\section{References}

[1] Doshi, J. and Reneker, D.H. (1995) Electrospinning Process and Applications of 
Electrospun Fibers. Journal of Electrostatics, 35, 151-160. https://doi.org/10.1016/0304-3886(95)00041-8

[2] Deitzel, J.M., Kleinmeyer, J. and Harris, D. (2001) The Effect of Processing Variables on the Morphology of Electrospun Nanofibers and Textiles. Polymer, 42, 261-272. https://doi.org/10.1016/S0032-3861(00)00250-0

[3] Li, D., Wang, Y. and Xia, Y. (2003) Electrospinning of Polymeric and Ceramic Nanofibers as Uniaxially Aligned Arrays. Nano Letters, 3, 1167-1171. https://doi.org/10.1021/nl0344256

[4] Jin, H.-J., Chen, J., Karageorgious, V., Altman, G.H. and Kaplan, D.L. (2004) Human Bone Marrow Stromal Cell Responses on Electrospun Silk Fibroin Mats. Biomaterials, 25, 1039-1047. https://doi.org/10.1016/S0142-9612(03)00609-4

[5] Wang, X., Kim, Y., Drew, C., Ku, B., Kuma, J. and Samuelson, L.A. (2004) Electrostatic Assembly of Conjugated Polymer Thin Layers on Electrospun Nanofibrous Membranes for Biosensors. Nano Letters, 4, 331-334. https://doi.org/10.1021/nl034885z

[6] Gibson, P., Schreuder-Gibson, H. and Rivin, D. (2001) Transport Properties of Porous Membranes Based on Electrospun Nanofibers. Colloids and Surfaces A, 187-188, 469-481. https://doi.org/10.1016/S0927-7757(01)00616-1

[7] Wang, M., Singh, H., Hatton, T.A., Rutledge, G.C. (2004) Field-Responsive Superparamagnetic Composite Nanofibers by Electrospinning. Polymer, 45, 5505-5514. https://doi.org/10.1016/j.polymer.2004.06.013

[8] Ma, M.L., Hill, R.M., Lowery, J.L., Fridrikh, S.V. and Rutledge, G.C. (2005) Electrospun Poly(styrene-block-dimethylsiloxane) Block Copolymer Fibers Exhibiting Superhydrophobicity. Langmuir, 21, 5549-5554. https://doi.org/10.1021/la047064y

[9] Taepaiboon, P., Rungsardthong, U. and Supaphol, P. (2007) Vitamin-Loaded Electrospun Cellulose Acetate Nanofiber Mats as Transdermal and Dermal Therapeutic Agents of Vitamin A Acid and Vitamin E. European Journal of Pharmaceutics and Biopharmaceutics, 67, 387-397. https://doi.org/10.1016/j.ejpb.2007.03.018

[10] Take, Y., Yoneda, M., Hayashida, K., Nakagawa, S. and Mizuno, N. (2008) Enlargement of Drill Holes after Use of a Biodegradable Suture Anchor: Quantitative Study on Consecutive Postoperative Radiographs. Arthroscopy, 24, 251-257. https://doi.org/10.1016/j.arthro.2008.01.007

[11] Barham, P.J. and Keller, A. (1985) High-Strength Polyethylene Fibres from Solution and Gel Spinning. Journal of Materials Science, 20, 2281-2302. https://doi.org/10.1007/BF00556059

[12] Reneker, D.H. and Chun, I. (1996) Nanometre Diameter Fibres of Polymer, Produced by Electrospinning. Nanotechnology, 7, 216-223. https://doi.org/10.1088/0957-4484/7/3/009

[13] Ren, J., Fu, H., Ren, T. and Yuan, W. (2009) Preparation, Characterization and Properties of Binary and Ternary Blends with Thermoplastic Starch, Poly(lactic acid) and Poly(butylene adipate-co-terephthalate). Carbohydrate Polymers, 77, 576-582. https://doi.org/10.1016/j.carbpol.2009.01.024

[14] Su, Z., Li, Q., Liu, Y., Hu, G.H. and Wu, C. (2009) Compatibility and Phase Structure of Binary Blends of Poly(lactic acid) and Glycidyl Methacrylate Grafted Poly(ethylene octane). European Polymer Journal, 45, 2428-2433. https://doi.org/10.1016/j.eurpolymj.2009.04.028

[15] Harada, M., Ohya, T., Iida, K., Hayashi, H., Hirano, K. and Fukuda, H. (2007) Increased Impact Strength of Biodegradable Poly(lactic acid)/Poly(butylene succinate) Blend Composites by Using Isocyanate as a Reactive Processing Agent. Journal of 
Applied Polymer Science, 106, 1813-1820. https://doi.org/10.1002/app.26717

[16] Noroozi, N., Schafer, L.L. and Hatzikiriakos, S.G. (2012) Thermorheological Properties of Poly( $\varepsilon$-caprolactone)/Polylactide Blends. Polymer Engineering \& Science, 52, 2348-2359. https://doi.org/10.1002/pen.23186

[17] Deng, Y. and Thomas, N.L. (2015) Blending Poly(butylene succinate) with Poly(lactic acid): Ductility and Phase Inversion Effects. European Polymer Journal, 71, 534-546. https://doi.org/10.1016/j.eurpolymj.2015.08.029

[18] Ren, M., Song, J., Song, C., Zhang, H., Sun, X., Chen, Q., Zhang, H. and Mo, Z. (2005) Crystallization Kinetics and Morphology of Poly(butylene succinate-co-adipate). Journal of Polymer Science Part B: Polymer Physics, 43, 3231-3241. https://doi.org/10.1002/polb.20539

[19] Zhao, J.-H., Wang, X.-Q., Zeng, J., Yang, G., Shi, F.-H. and Yan, Q. (2005) Biodegradation of Poly(butylene succinate) in Compost. Journal of Applied Polymer Science, 97, 2273-2278. https://doi.org/10.1002/app.22009

[20] Park, J.W. and Im, S.S. (2002) Phase Behavior and Morphology in Blends of Poly(L lactic acid) and Poly(butylene succinate). Journal of Applied Polymer Science, 86, 647-655. https://doi.org/10.1002/app.10923

[21] Chen, G.-X., Kim, H.-S., Kim, E.-S. and Yoon, J.-S. (2005) Compatibilization-Like Effect of Reactive Organoclay on the Poly(L-lactide)/Poly(butylene succinate) Blendsd. Polymer, 46, 11829-11836. https://doi.org/10.1016/j.polymer.2005.10.056

[22] Shibata, M., Inoue, Y. and Miyoshi, M. (2006) Mechanical Properties, Morphology, and Crystallization Behavior of Blends of Poly(L-lactide) with Poly(butylene succinate-co-L-lactate) and Poly(butylene succinate). Polymer, 47, 3557-3564. https://doi.org/10.1016/j.polymer.2006.03.065

[23] Yokohara, T. and Yamagushi, M. (2008) Structure and Properties for Biomass-Based Polyester Blends of PLA and PBS. European Polymer Journal, 44, 677-685. https://doi.org/10.1016/j.eurpolymj.2008.01.008

[24] Jompang, L., Thumsorn, S., WongOn, J., Surin, P., Apawet, C., Chaichalermwong, T., Kaabbuathong, N., O-Charoen, N. and Srisawat, N. (2013) Poly(lactic acid) and Poly(butylene succinate) Blend Fibers Prepared by Melt Spinning Technique. Energy Procedia, 34, 493-499. https://doi.org/10.1016/j.egypro.2013.06.777

[25] Hassan, E., Wei, Y., Jiao, H. and Muhuo, Y. (2013) Dynamic Mechanical Properties and Thermal Stability of Poly(lactic acid) and Poly(butylene succinate) Blends Composites. Journal of Fiber Bioengineering and Informatics, 6, 85-94.

[26] Peesan, M., Rujiravanit, R. and Supaphol, P. and Biomater, J. (2006) Electrospinning of Hexanoyl Chitosan/Polylactide Blends. Journal of Biomaterials Science, Polymer Edition, 17, 547-565. https://doi.org/10.1163/156856206776986251

[27] Li, X.J., Zhong, G.J. and Li, Z.M. (2009) Non-Isothermal Crystallization of Poly(L-lactide) (PLLA) under Quiescent and Steady Shear Conditions. Chinese Journal of Polymer Science, 28, 357-366. https://doi.org/10.1007/s10118-010-9015-Z

[28] Jeong, E.H., Im, S.S. and Youk, J.H. (2005) Electrospinning and Structural Characterization of Ultrafine Poly(butylene succinate) Fibers. Polymer, 46, 9538-9543. https://doi.org/10.1016/j.polymer.2005.07.100

[29] Liu, Y., He, J.H. and Yu, J.Y. (2007) Preparation and Morphology of Poly(butylene succinate) Nanofibers via Electrospinning. Fibres \& Textiles in Eastern Europe, 15, 30-33.

[30] Zong, X., Kim, K., Fang, D., Ran, S., Hsiao, B.S. and Chu, B. (2002) Structure and Process Relationship of Electrospun Bioabsorbable Nanofiber Membranes. Polymer, 
43, 4403-4412. https://doi.org/10.1016/S0032-3861(02)00275-6

[31] Cho, K., Lee, J. and Kwon, K. (2001) Hydrolytic Degradation Behavior of Poly(butylene succinate)s with Different Crystalline Morphologies. Journal of Applied Polymer Science, 79, 1025-1033. https://doi.org/10.1002/1097-4628(20010207)79:6<1025::AID-APP50>3.0.CO;2-7

[32] Spasova, M., Manolova, N., Paneva, D., Mincheva, R., Dubois, P., Rashkov, I., Maximova, V. and Danchev, D. (2010) Polylactide Stereocomplex-Based Electrospun Materials Possessing Surface with Antibacterial and Hemostatic Properties. Biomacromolecules, 11, 151-159. https://doi.org/10.1021/bm901016y

[33] Peesan, M., Supaphol, P. and Rujiravanit, R. (2005) Preparation and Characterization of Hexanoyl Chitosan/Polylactide Blend Films. Carbohydrate Polymers, 60, 343-350. https://doi.org/10.1016/j.carbpol.2005.01.008

[34] Dhanalakshmi, M. and Jog, J.P. (2008) Preparation and Characterization of Electrospun Fibers of Nylon 11. Express Polymer Letters, 2, 540-545. https://doi.org/10.3144/expresspolymlett.2008.65

[35] Wunderlich, B. (2005) Thermal Analysis of Polymeric Materials. Springer, Berlin. 